\title{
Synthesis of Southern Corn Rootworm Pheromone from S-Citronellol and Its Field Evaluation
}

\section{Thangaiah Subramanian1, Meiling Webb1, Ganga Bhagavathy1, Annett Rozek ${ }^{2}$, Bheema Rao Paraselli3 ${ }^{3}$ Kamlesh R. Chauhan ${ }^{*}$}

${ }^{1}$ Invasive Insects Biocontrol \& Behavior Laboratory, USDA-ARS, Beltsville, USA

${ }^{2}$ Terramera Inc., Vancouver, Canada

${ }^{3}$ Chemveda Life Sciences Inc., San Diego, USA

Email: *kamal.chauhan@ars.usda.gov

How to cite this paper: Subramanian, T., Webb, M., Bhagavathy, G., Rozek, A., Paraselli, B.R. and Chauhan, K.R. (2016) Synthesis of Southern Corn Rootworm Pheromone from S-Citronellol and Its Field Evaluation. Journal of Agricultural Chemistry and Environment, 5, 223-230.

http://dx.doi.org/10.4236/jacen.2016.54023

Received: September 27, 2016

Accepted: November 14, 2016

Published: November 17, 2016

Copyright $\odot 2016$ by authors and Scientific Research Publishing Inc. This work is licensed under the Creative Commons Attribution International License (CC BY 4.0).

http://creativecommons.org/licenses/by/4.0/

\begin{abstract}
Southern rootworm (Diabrotica undecimpunctata howardi) affects several plants such as soybean, sorghum, wheat, cucumber, alfalfa, cucurbits and it is most damaging to corn and peanuts. The pheromone based "attract and kill" strategy is one of the powerful ways to control pest population. To address our key objective of the practical utility of the synthetic pheromone, we have developed a simple synthetic strategy to produce gram scale southern corn rootworm pheromone in nine simple steps starting from $S$-Citronellol. The present strategy takes advantage of the existing chiral center of commercially available S-Citronellol. To get the basic carbon skeleton of the pheromone, the main step in the synthetic strategy is coupling of aliphatic units through Wittig reaction. The phosphonium salt from a non-functionalized aliphatic bromide followed by Wittig reaction improved the overall yield in the multistep synthesis of this pheromone. The large-scale production of pheromone enabled us to test it in the field.
\end{abstract}

\section{Keywords}

Southern Corn Rootworm, Pheromone Synthesis, Wittig Reaction, Diabrotica undecimpunctata howardi, Field Attraction

\section{Introduction}

The southern corn rootworm (SCR), the larvae of spotted cucumber beetle, has devastating impact on several grass crops mainly corn and peanuts in southern states. In re- 
cent times, there has been tremendous improvement in pest control including granular insecticides and genetic modification of plants [1] [2] [3]. On the other hand, synthetic insect sex pheromones play important roles in managing pest control through "attract and kill" strategy [4]. In this short communication, we are reporting an improved method for the large-scale synthesis of SCR pheromone for field trials. To illustrate with an example, we are reporting preliminary field study results conducted at the Beltsville Agriculture Research Center, Beltsville, MD.

The structure of this female-produced pheromone was identified by Tumlinson et al. as R-isomer of 10-methyl-2-tridecanone [5]. There have been many reports for the synthesis of the molecule [6] [7] [8] [9] some of them too complex and unadoptable for large scale production. Kenji Mori, a pioneer in this field has reported the synthesis of southern corn rootworm pheromone starting from R-(+)-Citronellol in eleven steps [10]. Our improved synthetic method (Figure 1), which is comparable to Kenji Mori's method, is adoptable for large scale synthesis, because it uses the commercially available cheap material (S)-Citronellol. The field study of natural pheromone and synthetic enantiomeric mixture has been reported showing the importance of the correct chiral center at C-10 of the SCR pheromone [5] for its effectiveness. Based on our knowledge, this is the first report for the enantiomerically pure synthetic pheromone being evaluated in the field.

\section{Materials and Methodology}

All chemical reagents were purchased from Sigma-Aldrich (St. Louis, MO). All solvents were bought from VWR as reagents grade and were used as such without further purification. Synthetic intermediates and sought compounds were characterized by ${ }^{1} \mathrm{H}$ NMR and GC-MS. ${ }^{1} \mathrm{H}$ NMR spectra of intermediates and final compound were obtained in $\mathrm{CDCl}_{3}$ as solvent with a Inova spectrometer operating at $400 \mathrm{MHz}$. Chemical shifts are reported in parts per million from the $\mathrm{CDCl}_{3}$ internal peak at $7.27 \mathrm{ppm}$ for ${ }^{1} \mathrm{H}$ (TSP, 0 ppm for ${ }^{1} \mathrm{H}$ ). The GC-MS spectra were recorded in Agilent GC-MS. All other chemicals used were reagent grade. All synthetic compounds were purified by silica gel column chromatography using ethyl acetate and hexanes as solvents unless otherwise noted.

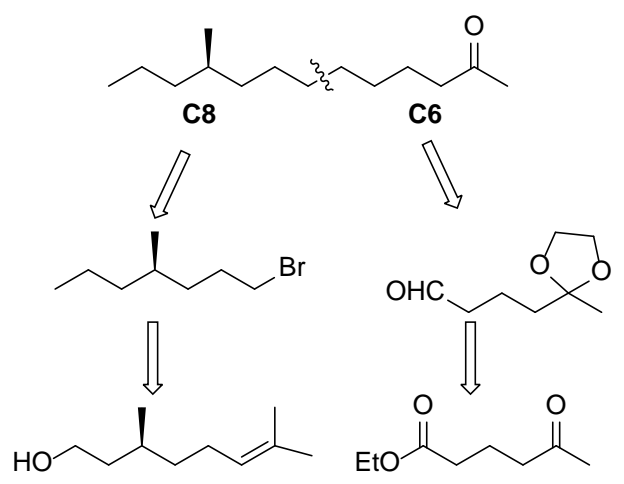

Figure 1. Retrosynthesis of (R)-10-methyltridecan-2-one from (S)-Citronellol. 
Our synthetic strategy is based on the goal of synthesizing this pheromone in large scale for the field test in a short time. The fragments identified were commercially S-Citronellol and ethyl 4-acteylbutyrate. The total synthesis of (R)-10-methyltridecan2-one has been achieved in 8 steps starting from (S)-citronellol in ca. 7\% overall yield.

Field trap evaluation was carried out in USDA BARC north farm. The septa were soaked in pheromone containing solvent and evaporated leaving pheromone in the septa. These rubber septa were inserted in to the traps and placed in the field along with the control traps. The beetles were counted during two week studies.

\section{Experimental Results}

The synthesis was carried out following the strategy shown in Figure 2 as follows. The S-Citronellyl bromide 2 was prepared from S-Citronellol using in-situ made dibromotriphenylphosphorane (71\%). The purified citronellyl bromide was converted into (R)-2,6-dimethylnon-2-ene by treating with in-situ made dimethyl copper lithium. The dimethyl copper lithium was made by treating methyl magnesium bromide in presence of $\mathrm{LiCl} / \mathrm{CuCl}_{2}$ (74\%) [11]. Over seven equivalents of methyl magnesium bromide were needed for the completion of the reaction for the highest yield. The resultant (R)-2,6dimethylnon-2-ene was subjected to ozonolysis to obtain (R)-4-methylheptanal 5 (88\%). The aldehyde was reduced to alcohol 6 by sodium borohydride with quantitative yield. The resultant (R)-4-methylheptan-1-ol was converted into (R)-1-bromo-4-methylheptane by in-situ made dibromotriphenyl phosphorane (61\%). Different conditions were attempted to make the Wittig salt using solvents but obtained highest yield $(87 \%)$ by heating with triphenylphosphine at $120^{\circ} \mathrm{C}$ in solvent free condition for 12 hours in a sealed tube. The aldehyde 4-(2-methyl-1,3-dioxolan-2-yl)butanal 9 required for the Wittig reaction was prepared in two steps starting from ethyl 4-acetylbutyrate following reported procedure [11]. The (R,E)-2-methyl-2-(8-methylundec-4-en-1-yl)1,3-dioxolane was prepared by Wittig reaction between compound salt 8 and aldehyde 9 using BuLi as a base at $-40^{\circ} \mathrm{C}$. The highest yield (32\%) was obtained under reaction condition. The cis-trans isomer was determined 12:88 by GC-MS (The high yields in

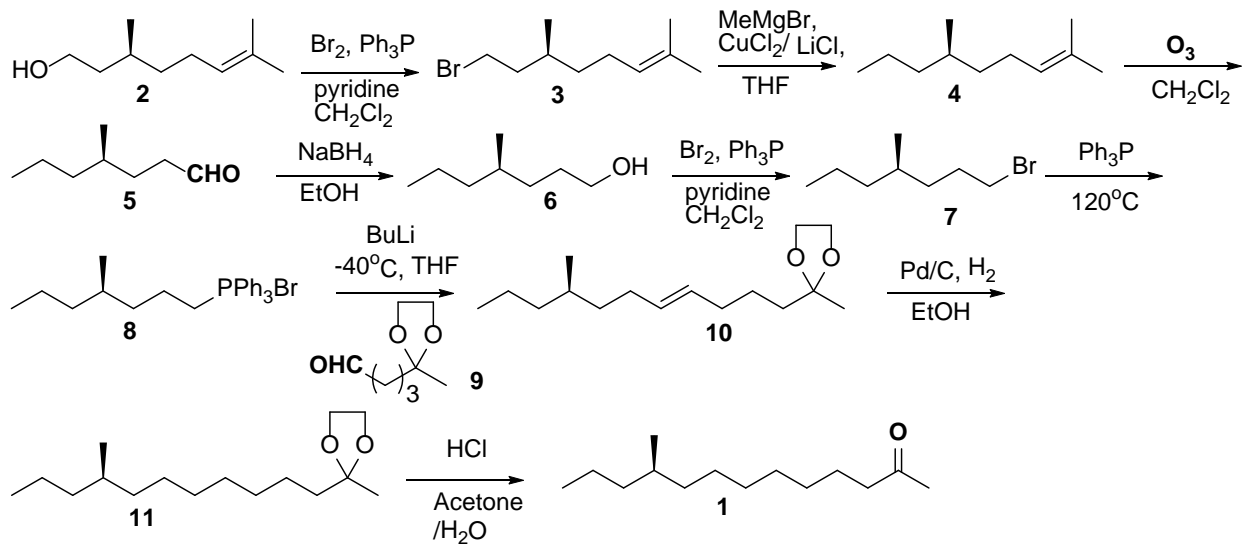

Figure 2. Synthesis of (R)-10-methyltridecan-2-one from (S)-Citronellol. 
the Wittig salt preparation and moderate yield in the Wittig reaction are the two steps that improved the overall yield compared with the reported procedure for the same intermediate [12]). The hydrogenation of (R,E)-2-methyl-2-(8-methylundec-4-en-1-yl)1,3-dioxolane using $\mathrm{Pd} / \mathrm{C}$ in ethanol yielded (R)-2-methyl-2-(8-methylundecyl)-1,3dioxolane. The required southern corn rootworm pheromone was released by deprotectionusing $\mathrm{HCl}$ in acetone/water. The final two steps gave quantitative yield.

\section{Synthesis of (S) -8-bromo-2,6-dimethyloct-2-ene, 3}

To a solution of triphenylphosphine $(15.72 \mathrm{~g}, 60 \mathrm{mmol})$ in methylene chloride at $0^{\circ} \mathrm{C}$ was added bromine till the color changes to yellow. Then the color of the solution was brought to colorless by adding a pinch of triphenylphosphine. After stirring for $10 \mathrm{mi}-$ nutes at $0^{\circ} \mathrm{C}$ citronellol $(7.80 \mathrm{~g}, 50 \mathrm{mmol})$ and $4.5 \mathrm{ml}$ of pyridine in dichloromethane $(10 \mathrm{ml})$ was added slowly. The resultant reaction mixture was stirred at the same temperature for 30 minutes and at room temperature for overnight. The crude mixture was concentrated to residue under reduced pressure. The residue was washed with hexanes $(75 \mathrm{ml} \times 3)$, washes were combined, concentrated and purified by silica gel column chromatography using hexanes and ethylacetate as solvents to obtain compound 3 (7.81 g, 71\%).

${ }^{1} \mathrm{H} \mathrm{NMR}\left(\mathrm{CDCl}_{3}\right) \delta 0.88(\mathrm{~d}, J=6.4 \mathrm{~Hz}, 3 \mathrm{H}), 1.11-1.20(\mathrm{~m}, 1 \mathrm{H}), 1.28-1.38(\mathrm{~m}, 1 \mathrm{H}), 1.59$ (s, 3H), 1.61-1.70 (m, 5H), 1.82-2.04 (m, 3H), 3.35-3.48 (m, 2H), 5.05-5.09 (m, 1H).

GC-MS (ESI) 219.

Synthesis of $(R)$-2,6-dimethylnon-2-ene, 4

To a solution of (S)-8-bromo-2,6-dimethyloct-2-ene (25 g, $114 \mathrm{mmol})$ dissolved in THF $(600 \mathrm{ml})$ at $0^{\circ} \mathrm{C}$, was added $\mathrm{LiCl}(8.59 \mathrm{~g}, 202 \mathrm{mmol})$ and $\mathrm{CuCl}_{2}(13.59 \mathrm{~g}, 101$ mmol) subsequently. The resultant reaction mixture was stirred at the same temperature and then methyl magnesium bromide $(300 \mathrm{ml}, 900 \mathrm{mmol}$ ) was added drop wise. The resultant reaction mixture was stirred at $0^{\circ} \mathrm{C}$ for an hour and at room temperature for overnight and finally refluxed for 3 hours before cooling it to $0^{\circ} \mathrm{C}$. The reaction was quenched with sat. $\mathrm{NH}_{4} \mathrm{Cl}$ solution $(20 \mathrm{~mL})$ at $0^{\circ} \mathrm{C}$ and the whole mixture was concentrated and washed with hexanes. The hexane washings were passed through a bed of silica gel. The filtrate was concentrated at reduced pressure and purified by silica gel column chromatography using hexanes and ethylacetate as solvents to obtain compound 4 (13.2 g, 74.7\%).

${ }^{1} \mathrm{H}$ NMR $\left(\mathrm{CDCl}_{3}\right) \delta 0.83-0.96(\mathrm{~m}, 6 \mathrm{H}), 1.03-1.75(\mathrm{~m}, 2 \mathrm{H}), 1.20-1.42(\mathrm{~m}, 6 \mathrm{H}), 1.58$ (s, 3H), $1.70(\mathrm{~s}, 3 \mathrm{H}), 1.88-2.05(\mathrm{~m}, 2 \mathrm{H}), 5.06-5.10(\mathrm{~m}, 1 \mathrm{H})$.

GC-MS (ESI) 154.

\section{Synthesis of $(R)$-4-methylheptanal, 5}

To the well cooled $\left(-78^{\circ} \mathrm{C}\right)$ solution of compound $4(11.5 \mathrm{~g}, 74.6 \mathrm{mmol})$ in methylene chloride $(150 \mathrm{~mL})$, was passed ozone till the color changes to light blue. Then $\mathrm{N}_{2}$ was passed for 30 minutes to remove the excess of ozone present in the solution. The ozonide was quenched with methyl sulfide solution $(50 \mathrm{ml})$ in methylene chloride (50 $\mathrm{mL}$ ) at the same temperature. The resultant reaction mixture was allowed to stir for 4 hours at room temperature. The entire solution was concentrated under reduced pres- 
sure at $5^{\circ} \mathrm{C}$. The resultant crude mixture was purified by column silica gel chromatography using hexanes and ethylacetate as solvents to obtain compound 5 (8.41 $\mathrm{g}, 88 \%)$.

${ }^{1} \mathrm{H}$ NMR $\left(\mathrm{CDCl}_{3}\right) \delta 0.81-0.90(\mathrm{~m}, 6 \mathrm{H}), 1.11-1.15(\mathrm{~m}, 1 \mathrm{H}), 1.20-1.34(\mathrm{~m}, 2 \mathrm{H}), 1.38$ $1.45(\mathrm{~m}, 2 \mathrm{H}), 1.60-1.69(\mathrm{~m}, 1 \mathrm{H}), 2.35-2.45(\mathrm{~m}, 2 \mathrm{H}), 9.75(\mathrm{t}, J=2 \mathrm{~Hz}, 1 \mathrm{H})$.

GC-MS (ESI): 128.

Synthesis of (R)-4-methylheptan-1-ol, 6

To a solution of compound $5(9.5 \mathrm{~g}, 74.2 \mathrm{mmol})$ in $\mathrm{EtOH}(50 \mathrm{~mL})$ at $0^{\circ} \mathrm{C}$ was added sodium borohydride $(2.81 \mathrm{~g}, 74.2 \mathrm{mmol})$ slowly. The resultant reaction mixture was stirred for 4 hours at the same temperature and quenched with water $(20 \mathrm{~mL})$. After stirring for 10 minutes water the entire solution was concentrated and extracted in ether, washed with brine, dried over $\mathrm{MgSO}_{4}$ and concentrated again. The crude material was purified by silica gel column chromatography using hexanes and ethyl acetate as solvents to obtain compound 6 (8.9 g, 92\%).

${ }^{1} \mathrm{H} \mathrm{NMR}\left(\mathrm{CDCl}_{3}\right) \delta 0.81-0.90(\mathrm{~m}, 6 \mathrm{H}), 1.10-1.25(\mathrm{~m}, 2 \mathrm{H}), 1.25-1.50(\mathrm{~m}, 5 \mathrm{H}), 1.50-$ $1.75(\mathrm{~m}, 2 \mathrm{H}), 3.64(\mathrm{t}, J=6.8 \mathrm{~Hz}, 2 \mathrm{H})$.

GC-MS (ESI): 130.

Synthesis of (R)-1-bromo-4-methylheptane, 7

To a solution of triphenylphosphine $(22.24 \mathrm{~g}, 84.9 \mathrm{mmol})$ in methylene chloride (150 $\mathrm{mL})$ at $0^{\circ} \mathrm{C}$ was added bromine till the color changes to yellow. Then the color of the solution was brought to colorless by adding a pinch of triphenylphosphine. The resultant mixture was stirred at $0^{\circ} \mathrm{C}$ and then added a mixture of alcohol $6(9.2 \mathrm{~g}, 70.7$ mmol) and pyridine $(6.28 \mathrm{ml})$ in methylene chloride $(20 \mathrm{ml})$. The resultant reaction mixture was stirred for an hour at the same temperature and at room temperature for overnight. The crude mixture was concentrated to residue under reduced pressure. The residue was washed with hexanes $(75 \mathrm{~mL} \times 3)$ and washes were combined, concentrated and purified by silica gel column chromatography using hexanes and ethylacetate as solvents to obtain bromide 7 ( $8.32 \mathrm{~g}, 61 \%)$.

${ }^{1} \mathrm{H}$ NMR $\left(\mathrm{CDCl}_{3}\right) 80.87-0.91(\mathrm{~m}, 6 \mathrm{H}), 1.10-1.20(\mathrm{~m}, 1 \mathrm{H}), 1.25-1.50(\mathrm{~m}, 6 \mathrm{H}), 1.75$ $2.0(\mathrm{~m}, 2 \mathrm{H}), 3.40(\mathrm{t}, J=6.4 \mathrm{~Hz}, 2 \mathrm{H})$.

GC-MS (ESI): 193.

Synthesis of (R)-bromo(4-methylheptyl) triphenyl-15-phosphane, 8

A mixture of triphenylphosphine $(11.32 \mathrm{~g}, 43.2 \mathrm{mmol})$ and bromide $7(8.3 \mathrm{~g}, 43.2$ $\mathrm{mmol}$ ) was heated to $120^{\circ} \mathrm{C}$ for 48 hours in a sealed tube which was pre-flushed with Argon before sealing. After allowing to room temperature the solid obtained was crushed into powder and washed with hexanes $(75 \mathrm{mlL} \times 3)$ thoroughly and dried under vacuum to obtain Wittig salt with a melting point of $168^{\circ} \mathrm{C}(17.13 \mathrm{~g}, 87.3 \%)$.

Synthesis of $(R, E)$-2-methyl-2-(8-methylundec-4-en-1-yI)-1,3-dioxolane, 10

To the suspended solution of compound $8(8.62 \mathrm{~g}, 18.98 \mathrm{mmol})$ in THF $(100 \mathrm{~mL})$ at $-40^{\circ} \mathrm{C}$ was added BuLi $(8.3 \mathrm{~mL} 2.5 \mathrm{M}, 20.87 \mathrm{mmol})$ slowly. The resultant mixture was stirred for 40 minutes at the same temperature and a solution of 4-(2-methyl-1,3-dioxolan-2-yl)butanal (3.00 g, $18.98 \mathrm{mmol})$ in THF $(10 \mathrm{~mL})$ dropwise. The resultant reaction mixture was stirred at the same temperature for 4 hours and $0^{\circ} \mathrm{C}$ temperature for 
12 hours. The reaction mixture was quenched with sat. $\mathrm{NH} 4 \mathrm{Cl}$ solution $(5 \mathrm{~mL})$, concentrated, extracted in ethyl acetate, washed with brine, dried over $\mathrm{MgSO}_{4}$ and concentrated again. The crude material was purified by silica gel column using hexanes and ethyl acetate as solvents to obtain compound 10 (1.57 g, 32\%).

${ }^{1} \mathrm{H}$ NMR $\left(\mathrm{CDCl}_{3}\right) 80.81-0.88(\mathrm{~m}, 6 \mathrm{H}), 1.00-1.19(\mathrm{~m}, 2 \mathrm{H}), 1.20-1.35(\mathrm{~m}, 5 \mathrm{H}), 1.36$ $1.48(\mathrm{~m}, 2 \mathrm{H}), 1.53(\mathrm{~s}, 3 \mathrm{H}), 1.57-1.67(\mathrm{~m}, 2 \mathrm{H}), 1.90-2.07(\mathrm{~m}, 4 \mathrm{H}), 3.87-3.95(\mathrm{~m}, 4 \mathrm{H})$, $5.27-5.38(\mathrm{~m}, 2 \mathrm{H})$.

GC-MS (ESI): 254.

Synthesis of $(R)$-2-methyl-2-(8-methylundecyl)-1,3-dioxolane, 11

A mixture of compound 10 (2.059 g, 8.1mmol) and $\mathrm{Pd} / \mathrm{C}(300 \mathrm{mg})$ in EtOH $(50 \mathrm{~mL})$ was stirred under $\mathrm{H}_{2}$ atmosphere was stirred at room temperature till starting material disappeared (about 24 hours). The $\mathrm{Pd} / \mathrm{C}$ was filtered out, the resultant solution was concentrated and purified by silica gel column chromatography using hexanes and ethyl acetate as solvents to compound 11 in quantitative yield $(2.06 \mathrm{~g})$.

${ }^{1} \mathrm{H}$ NMR $\left(\mathrm{CDCl}_{3}\right) \delta 0.81(\mathrm{~d}, J=6.4 \mathrm{~Hz}, 3 \mathrm{H}), 0.85(\mathrm{t}, J=6.8 \mathrm{~Hz}, 3 \mathrm{H}), 1.00-1.10(\mathrm{~m}$, $2 \mathrm{H}), 1.15-1.40(\mathrm{~m}, 15 \mathrm{H}), 1.54(\mathrm{~s}, 3 \mathrm{H}), 1.58-1.62(\mathrm{~m}, 2 \mathrm{H}), 3.87-3.95(\mathrm{~m}, 4 \mathrm{H})$.

GC-MS (ESI): 256.

Synthesis of $(R)$-10-methyltridecan-2-one, 1

To a cooled solution of compound $11(2.06 \mathrm{~g}, 8.04 \mathrm{mmol})$ in $50 \mathrm{~mL}$ of acetone/water mixture (4:1), was added $2 \mathrm{~mL}$ of $10 \% \mathrm{HCl}$ and the resultant reaction mixture was stirred at room temperature overnight. The resultant reaction mixture was concentrated and extracted with ethylacetate, washed with bicarbonate solution, washed with water, dried over $\mathrm{MgSO}_{4}$ and again concentrated. The crude product was purified by silica gel column chromatography using ethyl acetate and hexanes as solvents to obtain pheromone 1 in quantitative yield $(1.67 \mathrm{~g}, 98 \%)$.

${ }^{1} \mathrm{H} \mathrm{NMR}\left(\mathrm{CDCl}_{3}\right) \delta 0.81(\mathrm{~d}, J=6.4 \mathrm{~Hz}, 3 \mathrm{H}), 0.85(\mathrm{t}, J=6.8 \mathrm{~Hz}, 3 \mathrm{H}), 1.00-1.10(2 \mathrm{H}$, m), $1.17-1.40(\mathrm{~m}, 15 \mathrm{H}), 1.54(\mathrm{~s}, 3 \mathrm{H}), 1.58$ - $1.62(\mathrm{~m}, 2 \mathrm{H}), 2.38-2.42(\mathrm{~m}, 2 \mathrm{H})$.

GC-MS (ESI): 212.

\section{Preliminary Field Evaluation}

Field trap evaluation was carried out in USDA, BARC North farm (September-October 2015). The bucket traps of yellow and green funnel color (Figure 3) captured comparable numbers of SCR beetles. Only one striped beetle and two spotted beetles were caught in the control traps, whereas total 302 beetles were recovered in baited traps within the study period. We have reported only two weeks of results (Table 1 and Table 2) to avoid field condition variability. Males and females of SCR responded similarly and positively to the presence of 250 and 500 microgram pheromone lures. We could also see other beetles trapped in small numbers.

\section{Conclusion}

We have achieved total synthesis of SCR pheromone in a practically scalable route for the field study. In various combinations and settings, we utilized total $200 \mathrm{mg}$ of the 

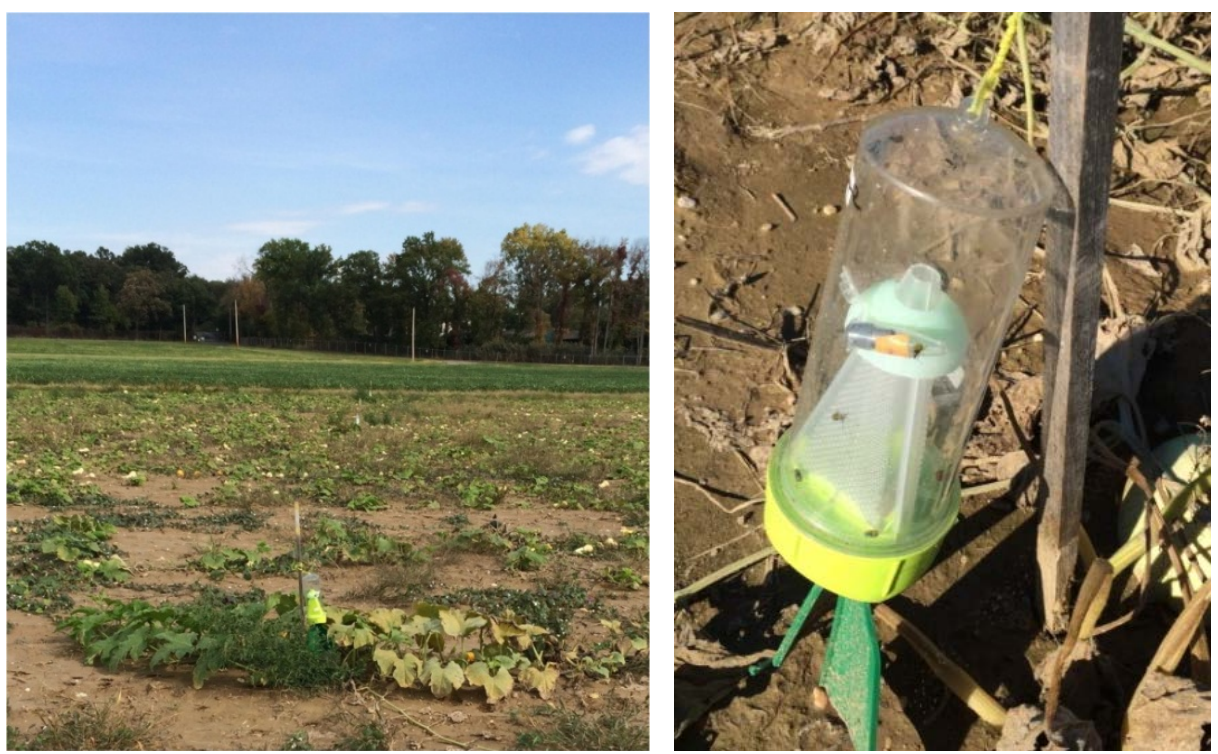

Figure 3. Field Evaluation: Pheromone traps were charged with two doses of the lures, $250 \mu \mathrm{g}$ and $500 \mu \mathrm{g}$ in duplicates. The squash field in the North farm of the Beltsville Agriculture Research Center was selected for natural abundance of SCR beetles. All traps were employed 25 meters apart in two rows. As shown in the photograph, all traps were hanged on wooden stick at $6 "-8$ " height above the ground near squash plants.

Table 1. Experiment in the week of Sept 28, 2015.

\begin{tabular}{ccc}
\hline Bait Formulation & SCR beetles & Striped beetles \\
\hline Lure 1 (250 ug) & 7 & 1 \\
lure 2 (250 ug) & 8 & 4 \\
Lure 3 (500 ug) & 12 & 0 \\
Lure 4 (500 ug) & 10 & 1 \\
Control & 2 & 0 \\
\hline
\end{tabular}

Table 2. Experiment in the week of Oct 5, 2015 (second week).

\begin{tabular}{ccc}
\hline Bait Formulation & SCR beetles & Striped beetles \\
\hline Lure 1 (250 ug) & 6 & 7 \\
lure 2 (250 ug) & 20 & 14 \\
Lure 3 (500 ug) & 10 & 2 \\
Lure 4 (500 ug) & 6 & 2 \\
Control & 0 & 1 \\
\hline
\end{tabular}

synthetic pheromone. Because of the weather fluctuations and hence limited time for field evaluation, we can report data of two weeks' time only. With natural abundance of all cucurbetacin beetles, the preliminary result showing greater than $80 \%$ response to SCR pheromone is very promising. Gram scale availability and economically viable synthetic aggregation pheromone will facilitate integrated pest management of SCR beetles in many important vegetable and cereal crops. 


\section{Acknowledgements}

Financial support from Terramera and Chemveda is gratefully acknowledged.

\section{References}

[1] Erbach, D.C. and Tollefson, J.J. (1983) Granular Insecticide Application for Corn Rootworm Control. Transactions of the ASAE, 26, 696-699. http://dx.doi.org/10.13031/2013.34005

[2] Gogos, A., Knauer, K. and Bucheli, T.D. (2012) Nanomaterials in Plant Protection and Fertilization: Current State, Foreseen Applications, and Research Priorities. Journal of Agricultural and Food Chemistry, 60, 9781-9792. http://dx.doi.org/10.1021/jf302154y

[3] Ferry, N., Edwards, M.G., Gatehouse, J., Capell, T., Christou, P. and Gatehouse, A.M.R. (2006) Transgenic Plants for Insect Pest Control: A Forward Looking Scientific Perspective. Transgenic Research, 15, 13-19. http://dx.doi.org/10.1007/s11248-005-4803-x

[4] Kabaluk, T.J., Lafontaine, J.P. and Borden, J.H. (2015) An Attract and Kill Tactic for Click Beetles Based on Metarhizium brunneum and a New Formulation of Sex Pheromone. Journal of Pest Science, 88, 707-716. http://dx.doi.org/10.1007/s10340-015-0661-3

[5] Guss, P.L., Tumlinson, J.H., Sonnet, P.E. and McLaughlin, J.R. (1983) Identification of a Female-Produced Sex Pheromone from the Southern Corn Rootworm. Diabrotica undecimpunctata howardi Barber. Journal of Chemical Ecololgy, 9, 1363-1375.

http://dx.doi.org/10.1007/BF00994805

[6] Enders, D. and Jandeleit, B. (1995) Efficient and Convergent Synthesis of (R)-(-)-10-Methyltridecan-2-One, the Sex-Pheromone of the Spotted Cucumber Beetle, by Iron-Mediated Chirality Transfer. Liebigs Annalen, 7, 1173-1176. http://dx.doi.org/10.1002/jlac.1995199507159

[7] Shikichi, Y. and Mori, K. (2000) Metathesis-Mediated Synthesis of (R)-10-Methyl-2-Tridecanone, the Southern Corn Rootworm Pheromone. Bioscience Biotechnology and Biochemistry, 76, 407-409. http://dx.doi.org/10.1271/bbb.110738

[8] Oppolzer, W., Dudfield, P., Stevenson, T. and Godel, T. (1985) Camphor SulfonamideShielded, Asymmetric 1,4-Additions and Enolate Alkylations; Synthesis of a Southern Corn Rootworm Pheromone. Helvetica Acta, 68, 212-215. http://dx.doi.org/10.1002/hlca.19850680126

[9] Shikichi, Y. and Mori, K. (2012) Synthesis of All the Stereoisomers of 6-Methyl-2-Octadecanone, 14-Methyl-2-Octadecanone, and 6,14-Dimethyl-2-Octadecanone, Sex Pheromone Components of the Lyclene Dharma Dharma Moth, from the Enantiomers of Citronellal. Bioscience Biotechnology and Biochemistry, 76, 1943-1951. http://dx.doi.org/10.1271/bbb.120436

[10] Senda, S. and Mori, K. (1983) Synthesis of (R)-(-)-10-Methyl-2-Tridecanone, the Pheromone of the Southern Corn Rootworm. Agricultural Biological Chemistry, 47, 795-798.

[11] Ogura, T. and Usuki, T. (2013) Total Synthesis of Acetogenins E, G and K, and Centrolobol. Tetrahedron, 69, 2807-2815.

[12] Odinokov, V.N., Kukovinets, O.S., Kasradze, V.G., Tsyglintseva, E.Yu., Serebryakov, E.P. and Tolstikov, G.A. (1992) Insect Pheromones and Their Analogues. xxxv. Synthesis of (r)-(-)-10-Methyltridecan-2-One-The Pheromone of Diabrotica undecimpunctata. Chemistry of Natural Compounds, 28, 106-109. http://dx.doi.org/10.1007/BF00629806 
Submit or recommend next manuscript to SCIRP and we will provide best service for you:

Accepting pre-submission inquiries through Email, Facebook, LinkedIn, Twitter, etc. A wide selection of journals (inclusive of 9 subjects, more than 200 journals)

Providing 24-hour high-quality service

User-friendly online submission system

Fair and swift peer-review system

Efficient typesetting and proofreading procedure

Display of the result of downloads and visits, as well as the number of cited articles

Maximum dissemination of your research work

Submit your manuscript at: http://papersubmission.scirp.org/

Or contact jacen@scirp.org 